\title{
Obesity and Remission Rates in Japanese Patients With Rheumatoid Arthritis Requiring Anti-Tumor Necrosis Factor Alpha Therapy
}

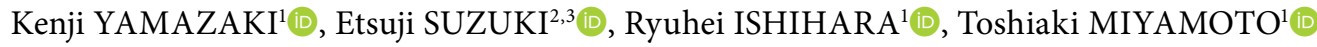 \\ ${ }^{1}$ Department of Rheumatology, Seirei Hamamatsu General Hospital, Shizuoka, Japan \\ ${ }^{2}$ Department of Epidemiology, Graduate School of Medicine, Dentistry and Pharmaceutical Sciences, Okayama University, Okayama, Japan \\ ${ }^{3}$ Department of Epidemiology, Harvard T.H. Chan School of Public Health, Boston, MA, United States
}

\begin{abstract}
Objectives: This study aims to determine if obesity is a risk factor for a poor response to anti-tumor necrosis factor alpha (anti-TNFa) therapy in Japanese patients with rheumatoid arthritis (RA) using the appropriate body mass index (BMI) cut-off points for Asian populations.

Patients and methods: This retrospective cohort study evaluated 382 outpatients with RA (98 males, 284 females; mean age 54.2 years; range, 18 to 84 years) who had received anti-TNFa therapy between May 2009 and July 2017. Patients were classified according to BMI at baseline as follows: $<18.5 \mathrm{~kg} / \mathrm{m}^{2}$ (underweight), $18.5-23.0 \mathrm{~kg} / \mathrm{m}^{2}$ (normal weight), $23.0-27.5 \mathrm{~kg} / \mathrm{m}^{2}$ (overweight), and $\geq 27.5 \mathrm{~kg} / \mathrm{m}^{2}$ (obese). The response variable was defined as Simplified Disease Activity Index (SDAI) remission after 12 months. We estimated odds ratios (ORs) and their $95 \%$ confidence intervals ( $\mathrm{Cls}$ ) for poor response to the therapy.

Results: After 87 patients were excluded, $183(62.0 \%)$ of 295 had reached remission at the 12-month follow-up. Compared with normal-weight patients, the multivariate OR for poor response of obese patients was $2.2(95 \% \mathrm{Cl}: 0.5-9.4)$. Adjusting for the baseline SDAl score, the corresponding OR was $1.8(0.4-7.6)$

Conclusion: We found no statistically significant association between obesity and poor response to anti-TNFa therapy in Japanese patients with RA. Because this may partly be due to the limited statistical power of our study, further research is warranted to examine the possible effect modification across countries.

Keywords: Anti-tumor necrosis factor alpha, Japanese, obesity, remission, rheumatoid arthritis.
\end{abstract}

Obesity is associated with several diseases, including diabetes mellitus, hypertension, and coronary artery disease. There is a growing recognition that overproduction of a variety of adipokines by adipocytes caused by a chronic inflammatory state has a significant role in obesity. ${ }^{1}$ These adipokines act as specific immunomodulatory factors generating pro-inflammatory responses and stimulating a diverse set of immune cells. ${ }^{2}$ This perspective has led to a major interest in the relationship between obesity and autoimmune disease at present.
Because leptin, adiponectin, and visfatin are upregulated in patients with rheumatoid arthritis (RA), ${ }^{3}$ obesity may affect its natural history, including disease onset, activity, response to therapy, and prognosis. ${ }^{4-6}$

Since the introduction of anti-tumor necrosis factor alpha (anti-TNF- $\alpha$ ) therapy, the prognosis of RA has improved in many patients. However, unfortunately, some patients have not reached their goals. Several studies have reported that obesity may be a risk factor for poor response

Received: October 17, 2019 Accepted: December 28, 2019 Published online: June 25, 2020

Correspondence: Kenji Yamazaki, MD, PhD. Department of Rheumatology, Seirei Hamamatsu General Hospital, 430-8558 Shizuoka, Japan. Tel: 81-53-474-2222 e-mail: rav4skypares@yahoo.co.jp

\section{Citation:}

Yamazaki K, Suzuki E, Ishihara R, Miyamoto T. Obesity and Remission Rates in Japanese Patients With Rheumatoid Arthritis Requiring Anti-Tumor Necrosis Factor Alpha Therapy. Arch Rheumatol 2020;35(4):600-608. 
to anti-TNF- $\alpha$ therapy, ${ }^{7-10}$ which reduces the drug survival of anti-TNF- $\alpha$ therapy in patients with $\mathrm{RA}^{11}$ Despite the increasing interest in this subject, evidence remains sparse, particularly in the Japanese population. One possible reason is the shared genetic risks for RA being slightly different between Japanese and European populations, which may yield different associations between obesity and response to anti-TNF- $\alpha$ therapy in Japanese RA at real world setting compared with previous report. ${ }^{12}$ And with respect to responsiveness to antirheumatic drugs, ethnic differences in the sensitivity to certain classes of drug, such as leflunomide, have indeed been identified. ${ }^{13}$ Furthermore, Asian populations have different associations between body mass index (BMI), percentage of body fat, and health risks than those of Western populations. ${ }^{14}$ To address this problem, a World Health Organization (WHO) consultation report proposed appropriate BMI cut-off points for Asian populations and redefined obesity as BMI $>27.5 \mathrm{~kg} / \mathrm{m}^{2}{ }^{14}$ From the perspective of exploring the association of obesity and the response to RA after anti-TNF- $\alpha$ therapy, it is vital to clearly define "obesity" for an appropriate ethnic group. Therefore, in this study, we aimed to determine if obesity is a risk factor for a poor response to anti-TNF- $\alpha$ therapy in Japanese patients with RA using the appropriate BMI cut-off points for Asian populations.

\section{PATIENTS AND METHODS}

Individual data were retrospectively collected from patients who visited Seirei Hamamatsu General Hospital in Japan between May 2009 and July 2017. All the eligible patients fulfilled the 2010 American College of Rheumatology (ACR)/ European League Against Rheumatism (EULAR) criteria for $\mathrm{RA}^{15}$ and had inadequate response to at least one disease-modifying antirheumatic drug or immunosuppressant, including methotrexate. To minimize the extent of weight change during the study period, we excluded the patients who suffered from other constitutional diseases (e.g., hypothyreosis, chronic kidney disease). Subsequently, we selected patients with RA who had an active moderate-to-severe disease in spite of treatment with methotrexate at the usual dosage of $12-16 \mathrm{mg} /$ week according to their tolerability and put them on adalimumab as an
anti-TNF- $\alpha$ drug with the aim of reaching the best possible outcome. Thus, a total of 382 RA patients (98 males, 284 females; mean age 54.2 years; range, 18 to 84 years) were included. Adalimumab was given according to the usual schedule; i.e., $40 \mathrm{mg}$ subcutaneously every two weeks. The study protocol was approved by the Seirei Hamamatsu General Hospital Ethics Committee (May 16, 2018; No. 2732). A written informed consent was obtained from each patient. The study was conducted in accordance with the principles of the Declaration of Helsinki and the ethical guidelines for epidemiologic research in Japan.

The self-administered questionnaire inquired about age, sex, body weight, height, smoking habits, and disease duration. BMI was calculated as weight $(\mathrm{kg})$ divided by the square of height (m) at the baseline of the therapy. Following the WHO guidelines, the participants were classified by using an appropriate BMI for Asian populations as follows: $<18.5 \mathrm{~kg} / \mathrm{m}^{2}$ (underweight), $18.5-23.0 \mathrm{~kg} / \mathrm{m}^{2}$ (normal weight), $23.0-27.5 \mathrm{~kg} / \mathrm{m}^{2}$ (overweight), and $\geq 27.5 \mathrm{~kg} / \mathrm{m}^{2}$ (obese). These cut-off points were proved to be appropriate in an earlier study that examined the prevalence of obesity and type 2 diabetes. ${ }^{16}$ Furthermore, the pooled analysis by Sasazuki et al. ${ }^{17}$ showed the risk of excess weight $\left(\mathrm{BMI} \geq 27.0 \mathrm{~kg} / \mathrm{m}^{2}\right.$ ) on mortality among middleaged Japanese adults and concluded that a BMI $\geq 27.0 \mathrm{~kg} / \mathrm{m}^{2}$ should be defined as a high-risk group for all-cause mortality. These results are consistent with the new definition of obesity in the Asian population.

From the records, we obtained a serological test to examine immunoglobulin $\mathrm{M}$ rheumatoid factor (RF) and anti-cyclic citrullinated peptide (anti-CCP) antibody. We categorized patients with $\mathrm{RF}>20 \mathrm{IU} / \mathrm{mL}$ and anti-CCP antibody $>5 \mathrm{U} / \mathrm{mL}$ as seropositive. Additionally, we individually assessed Steinbrocker's stages on X-ray and Steinbrocker's functional classes at the baseline. ${ }^{18}$ Clinical information, including current and previous medication for RA, tender and swollen joint counts in 28 joints, patient's and physician's global visual analog scale (VAS), erythrocyte sedimentation rate (ESR), serum levels of C-reactive protein (CRP), and the Health Assessment Questionnaire (HAQ) Disability Index were collected at every visit from the 
start of anti-TNF- $\alpha$ drug. A Simplified Disease Activity Index (SDAI) was used to assess the outcome, and we defined non-remission as an SDAI $\geq 3.3$ after 12 months. ${ }^{19}$ The SDAI is the numerical sum of five outcome parameters: tender and swollen joint counts in 28 joints, patient's and physician's global VAS, and CRP level. In addition, we considered those who had to terminate the anti-TNF- $\alpha$ therapy because of non-response as non-responders. Non-responders were allocated $<12$ months at the discretion of the rheumatologist based on the idea that the patients will inevitably experience non-remission at the 12-month follow-up, that is, they were rated as no response by the EULAR response criteria after about six months. ${ }^{20}$ Namely, the total number of poor responses to the anti-TNF- $\alpha$ therapy was the sum of nonremission after the 12-month follow-up and nonresponders. We excluded the patients who were lost to follow-up within 12 months for reasons other than non-responder.

We considered the following variables to be potential confounders: age at baseline (continuous), sex, smoking status (current/former smoker versus [vs.] never smoker), RF status ( $>20 \mathrm{IU} / \mathrm{mL}$ vs. $\leq 20 \mathrm{IU} / \mathrm{mL}$ ), anti-CCP antibody status ( $>5 \mathrm{U} / \mathrm{mL}$ vs. $\leq 5 \mathrm{U} / \mathrm{mL}$ ), and disease duration (months).

\section{Statistical analysis}

First, a descriptive analysis was performed for the demographic characteristics according to follow-up status and the baseline BMI categories. Next, we calculated crude odds ratios (ORs) and 95\% confidence intervals (CIs) for poor response to anti-TNF- $\alpha$ therapy by using a logistic regression model. Subsequently, we estimated age- and sex-adjusted ORs and multivariate ORs. Furthermore, we performed a sensitivity analysis by using another remission defined as the Disease Activity Score that included a 28-joint count (DAS28)-ESR score $<2.6 .^{19}$ DAS28-ESR is a combined index that was developed in Nijmegen in the 1980s to measure the disease activity in patients with RA. In addition, we carried out a sensitivity analysis using WHO international cut-off points $\left(<18.5 \mathrm{~kg} / \mathrm{m}^{2}\right.$ for underweight, $18.5-25.0 \mathrm{~kg} / \mathrm{m}^{2}$ for normal weight, $25.0-30.0 \mathrm{~kg} / \mathrm{m}^{2}$ for overweight and $\geq 30.0 \mathrm{~kg} / \mathrm{m}^{2}$ for obese). All statistical analyses were performed by using EZR version 1.24 (Saitama Medical Center, Jichi Medical University, Saitama, Japan), a graphical user interface for $\mathrm{R}$ (The R Foundation for Statistical Computing, Vienna, Austria). More precisely, it is a modified version of $\mathrm{R}$ Commander designed to add statistical functions frequently used in biostatistics. ${ }^{21}$

\section{RESULTS}

All 382 patients were monitored regularly (Figure 1). We restricted the participants according to the standard of care, including non-responders switching from adalimumab. Consequently, 87 patients who were lost to follow-up for reasons other than of non-response $(n=43)$ and those who had been followed for

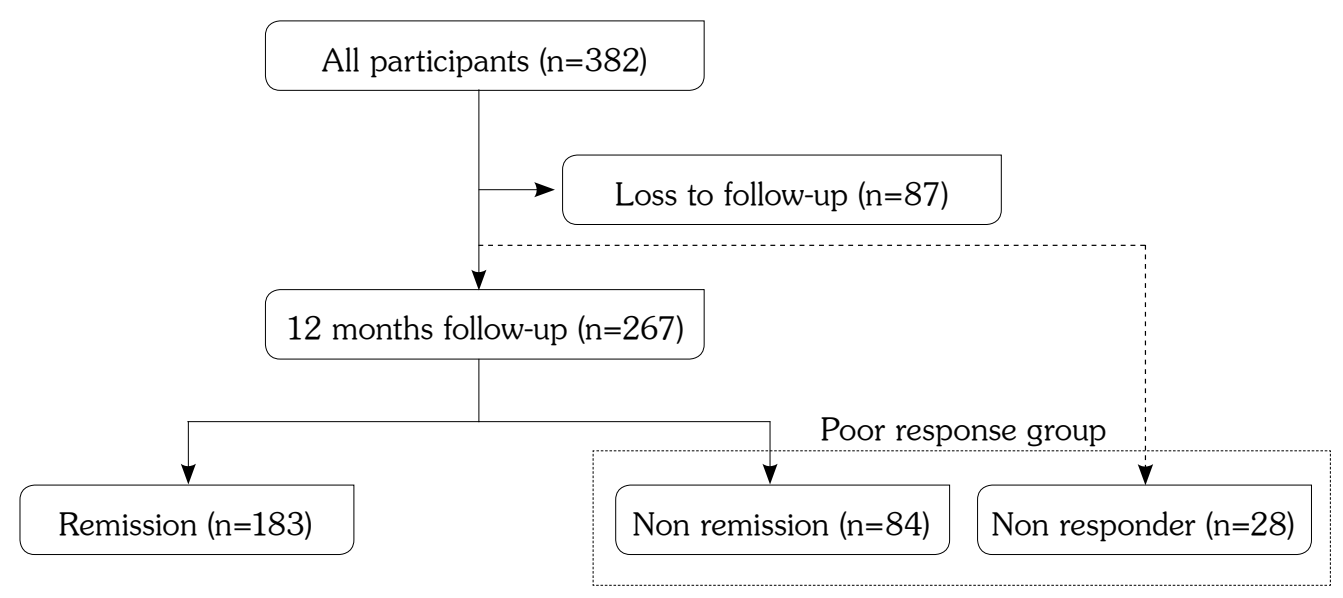

Figure 1. Patient flowchart. 


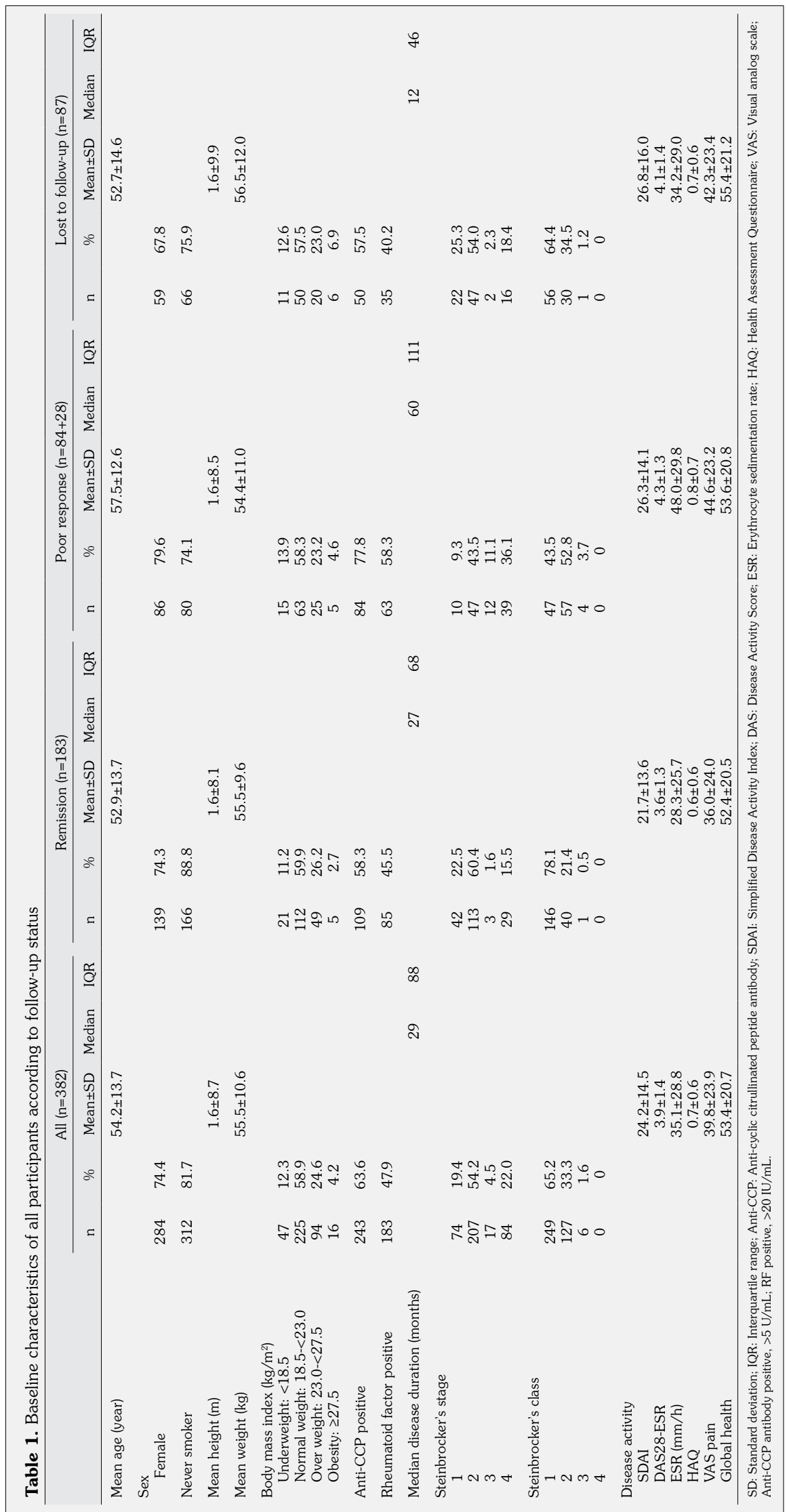




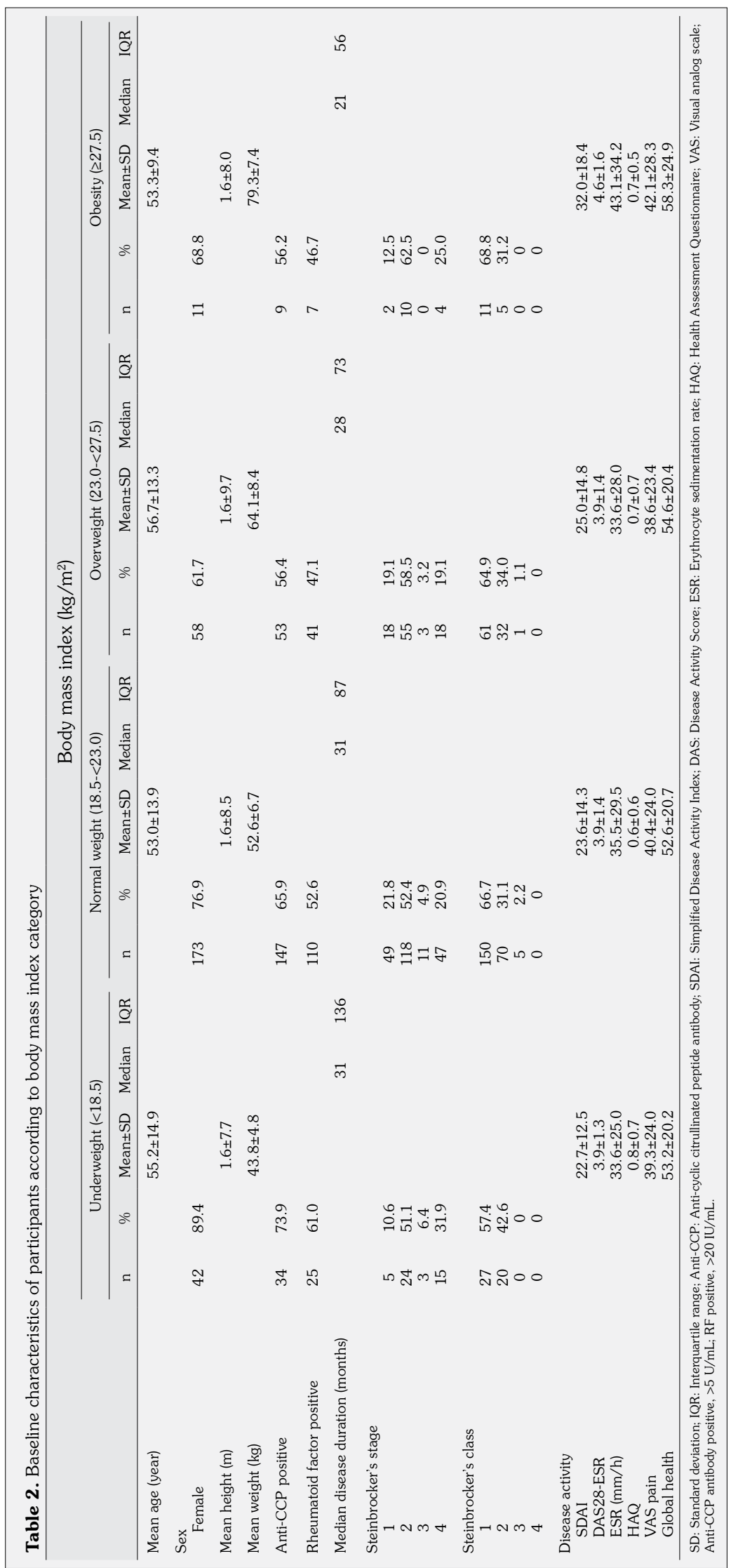


Table 3. Number and odds ratios for poor response assessed by Simplified Disease Activity Index to anti-tumor necrosis factor alpha therapy by appropriate body mass index category for an Asian population

\begin{tabular}{|c|c|c|c|c|c|c|c|c|c|c|c|c|}
\hline & \multicolumn{12}{|c|}{ Body mass index $\left(\mathrm{kg} / \mathrm{m}^{2}\right)$} \\
\hline & \multicolumn{3}{|c|}{ Underweight $(<18.5)$} & \multicolumn{3}{|c|}{ Normal weight $(18.5-<23.0)$} & \multicolumn{3}{|c|}{ Overweight $(23.0-<27.5)$} & \multicolumn{3}{|c|}{ Obese $(\geq 27.5)$} \\
\hline & $\mathrm{n}$ & OR & $95 \% \mathrm{CI}$ & $\mathrm{n}$ & OR & $95 \% \mathrm{CI}$ & $\mathrm{n}$ & OR & $95 \% \mathrm{CI}$ & $\mathrm{n}$ & OR & $95 \% \mathrm{CI}$ \\
\hline $\begin{array}{l}\text { Total number of } \\
\text { Poor responses } \\
\text { Non-responders }\end{array}$ & $\begin{array}{c}16 \\
3\end{array}$ & & & $\begin{array}{l}66 \\
19\end{array}$ & & & $\begin{array}{c}24 \\
5\end{array}$ & & & $\begin{array}{l}6 \\
1\end{array}$ & & \\
\hline Crude & & 1.3 & $0.6-2.7$ & & 1.0 & & & 0.8 & $0.5-1.4$ & & 2.5 & $0.7-9.1$ \\
\hline Age-sex-adjusted & & 1.3 & $0.6-2.8$ & & 1.0 & & & 0.7 & $0.4-1.3$ & & 2.4 & $0.6-8.8$ \\
\hline \multicolumn{13}{|l|}{$\begin{array}{l}\text { Multivariate odds } \\
\text { ratios }\end{array}$} \\
\hline Model $1 \dagger$ & & 1.2 & $0.5-2.8$ & & 1.0 & & & 0.7 & $0.4-1.4$ & & 1.8 & $0.4-7.6$ \\
\hline Model $2 \neq$ & & 1.2 & $0.5-2.8$ & & 1.0 & & & 0.7 & $0.4-1.4$ & & 1.8 & $0.4-7.6$ \\
\hline Model 3वा & & 1.5 & $0.7-3.6$ & & 1.0 & & & 0.8 & $0.4-1.6$ & & 1.7 & $0.4-8.0$ \\
\hline
\end{tabular}

$<12$ months $(\mathrm{n}=44)$ were excluded. Among the remaining 295 patients, 28 (1\%) were censored as non-responders. At the 12-month follow-up, 183 patients $(62.0 \%)$ of the 295 had reached SDAI remission. Table 1 shows the baseline characteristics of the 382 patients according to their follow-up status. A BMI $\geq 27.5 \mathrm{~kg} / \mathrm{m}^{2}$ (obesity) was recorded in 16 (4.2\%) of 382. Table 2 shows the baseline characteristics of the patients according to BMI categories. Obese patients were more likely to have never smoked (never smoker,
62.5\%), seronegative (anti-CCP antibody positive $57.5 \%$ and RF positive $40.2 \%$ ), and have shorter disease duration (interquartile range, 12 months). Regarding disease activity, the obese patients' composite measure and component parameters tended to be slightly higher.

Table 3 shows crude and adjusted ORs for poor response to anti-TNF- $\alpha$ therapy. Adjusting for confounders, the estimated odds of poor response among obese patients were more than doubled relative to those of normal patients, but it

Table 4. Number and odds ratios for poor response assessed by Simplified Disease Activity Index to anti-tumor necrosis factor alpha therapy by World Health Organization standard body mass index category

\begin{tabular}{|c|c|c|c|c|c|c|c|c|c|c|c|c|}
\hline & \multicolumn{12}{|c|}{ Body mass index $\left(\mathrm{kg} / \mathrm{m}^{2}\right)$} \\
\hline & \multicolumn{3}{|c|}{ Underweight $(<18.5)$} & \multicolumn{3}{|c|}{ Normal weight $(18.5-<25.0)$} & \multicolumn{3}{|c|}{ Overweight $(25.0-<30.0)$} & \multicolumn{3}{|c|}{ Obese $(\geq 30.0)$} \\
\hline & $\mathrm{n}$ & OR & $95 \% \mathrm{CI}$ & $\mathrm{n}$ & OR & $95 \% \mathrm{CI}$ & $\mathrm{n}$ & OR & $95 \% \mathrm{CI}$ & $\mathrm{n}$ & OR & $95 \% \mathrm{CI}$ \\
\hline $\begin{array}{l}\text { Total number of } \\
\text { Poor responses } \\
\text { Non-responders }\end{array}$ & $\begin{array}{c}16 \\
3\end{array}$ & & & $\begin{array}{l}83 \\
24\end{array}$ & & & $\begin{array}{l}9 \\
0\end{array}$ & & & $\begin{array}{l}4 \\
1\end{array}$ & & \\
\hline Crude & & 1.3 & $0.7-2.7$ & & 1.0 & & & 0.7 & $0.3-1.6$ & & 3.4 & $0.6-18.7$ \\
\hline $\begin{array}{l}\text { Multivariate odds } \\
\text { ratios }\end{array}$ & & & & & & & & & & & & \\
\hline Model $1 \dagger$ & & 1.1 & $0.5-2.6$ & & 1.0 & & & 0.7 & $0.3-1.7$ & & 2.5 & $0.4-16.3$ \\
\hline Model 2‡ & & 1.3 & $0.6-2.9$ & & 1.0 & & & 0.7 & $0.3-1.8$ & & 2.8 & $0.5-17.9$ \\
\hline
\end{tabular}

OR: Odds ratio; $\mathrm{Cl}$ : Confidence interval; $†$ Age, sex, smoking status, anti-cyclic citrullinated peptide antibody status, rheumatoid factor status, disease duration, and baseline Steinbrocker's stage were adjusted; $\neq$ Age, sex, smoking status, anti-cyclic citrullinated peptide antibody status, rheumatoid factor status, disease duration, and baseline Simplified Disease Activity Index were adjusted. 
was not statistically significant (OR: 2.2, 95\% CI: 0.5-9.4). Adjusting for the baseline SDAI score, the association was attenuated toward the null (OR: 1.8, 95\% CI: 0.4-7.6). To improve analytical sensitivity, we re-analyzed after excluding the nonresponders and found no clear association between obesity and remission rate. When we alternatively used DAS28-ESR $<2.6$ as an outcome, no substantial change was observed (data not shown). In addition, when using the WHO standard BMI cut-off values, no clear association was found between obesity and remission rate (Table 4).

\section{DISCUSSION}

Using appropriate BMI cut-off points for Asian populations, we examined whether obesity is a risk factor for a poor response to anti-TNF- $\alpha$ therapy in Japanese patients with RA. Compared with normal-weight patients, the point estimates of ORs for poor response of obese patients were approximately doubled. However, these associations were not statistically significant, which is inconsistent with the previous studies from Western countries. ${ }^{7-10}$

A previous study from Italy reported that obesity was an additional risk for not reaching remission in patients with $\mathrm{RA}$ receiving the first anti-TNF- $\alpha$ drug because of active disease under disease-modifying antirheumatic drug conventional therapy, for which the remission rate at 12 months was lower in obese patients (15.2\%) than in normal-weight patients (32.9\%). ${ }^{7}$ Another study from Italy also showed that obese patients had the highest hazard for discontinuation of the first anti-TNF- $\alpha$ drug (hazard ratio: $1.64,95 \% \mathrm{CI}$ : 1.02-2.62). ${ }^{11}$ Given the similar point estimates, one possibility of our inconsistent findings is a lack of statistical power of our study. Notably, however, our results showed that the baseline disease activity across BMI groups substantially varied; obese patients tended to have higher disease activity at the baseline. This raises the possibility that the present findings might not be related to the anti-TNF- $\alpha$ therapy pathway. On a related issue, Ajeganova et al. ${ }^{5}$ found that obesity was directly correlated with higher disease activity. On the other hand, Choe et al. ${ }^{22}$ found no association between BMI and disease activity composites of RA in a Korean population.
Although no conclusive claims can be made regarding these alternative explanations, when we re-analyzed our data by adjusting for baseline SDAI score, ORs for poor response were slightly attenuated (Table 3). Therefore, our findings suggest that a poor response to anti-TNF- $\alpha$ therapy among obese patients was derived not only from higher disease activity.

The mechanisms underlying the relationship between obesity and response to anti-TNF- $\alpha$ therapy remain speculative. First, regarding the effect of obesity on the pharmacokinetics of drugs in humans, there are several relevant complicated factors, including absorption, volume distribution, and clearance. ${ }^{23}$ Although drug lipophilicity is an imperfect measure to predict drug distribution in obese individuals, it contributes substantially to the variance in calculated peripheral compartment volumes of distribution. However, this distribution is not well understood because there are other important determinants of distribution, e.g., tissue binding, organ blood flow, drug plasma protein binding, and the ionization state. Second, T-helper 17 (Th17) cells may have an important role in linking obesity and RA. Obesity can produce excessive Th17 cells/interleukin (IL)-17 secretion by several pathways, including a direct pathway, an overproduction of adipokines pathway, a fatty food pathway, and a vitamin D deficiency pathway. ${ }^{2}$ In a previous experimental study, obese inflammatory arthritis model mice showed higher IL-17 expression on synovium in immunohistochemical analysis than that in lean mice. ${ }^{24}$ Hence, IL-17 is a pivotal cytokine for acceleration of joint inflammation in obesity. On the other hand, Alzabin et al. ${ }^{25}$ reported an inverse relationship between baseline Th17 levels and the subsequent response of patients with RA to antiTNF- $\alpha$ therapy. Therefore, we speculate that RA among obese patients induces higher Th17 cells/ IL-17 secretion, which may in turn yield higher resistance to anti-TNF- $\alpha$ therapy. Consistent with this, Shan et al. ${ }^{26}$ showed that obesity did not hamper the effect of T-cell activation inhibition by abatacept and IL- 6 inhibition by tocilizumab, which are assumed to be less influenced by the Th17 cascade.

There were some limitations in this study. First, differential misclassification of the outcome might have occurred because of the composite measure. A previous meta-analysis 
showed that obesity in RA was associated with increased DAS28 and HAQ scores and with lower radiographic joint damage. ${ }^{27}$ These associations mainly resulted from an increase in the subjective components of the DAS28 in obese patients. If this misclassification occurred in the present study, we might have overestimated the influence of obesity. Second, arthritis is a common manifestation of other diseases (e.g., osteoarthritis) associated with obesity. If obese patients with RA tended to have more complicated osteoarthritis, it is possible that we overestimated the influence of obesity. However, to address this issue, we paid close attention to differential osteoarthritis by regularly using X-ray assessments as well as conducting ultrasonographic assessments when necessary. Finally, because BMI was only recorded at the baseline, we did not examine possible weight change during the study period. To partly address this issue, we excluded the subjects who suffered from other constitutional diseases, because they are more likely to experience weight change. Furthermore, given that the follow-up period of this study was relatively short (i.e., 12 months), substantial weight change is less likely to occur in most subjects, which we believe did not significantly influence the study results. The obesity paradox is a well-known phenomenon that shows a survival advantage of being obese. Notably, Ajeganova et al. ${ }^{5}$ also showed evidence of the obesity paradox in patients with RA; patients with high BMI had lower mortality than that of thinner patients. However, this phenomenon may not be a true causal relationship because it may be the result of reverse causation, residual confounding, survival advantages, and statistical methods. ${ }^{28}$

In conclusion, we found no statistically significant association between obesity and poor response to anti-TNF- $\alpha$ therapy in Japanese patients with RA, which is inconsistent with previous studies from Western countries.7-10 Because this may partly be due to the limited statistical power of our study, further research is warranted to examine the possible effect modification across countries.

\section{Declaration of conflicting interests}

The authors declared no conflicts of interest with respect to the authorship and/or publication of this article.

\section{Funding}

ES was supported by the Japan Society for the Promotion of Science (KAKENHI Grant Numbers JP17K17898 and JP18K10104) and the Okayama Medical Foundation.

\section{REFERENCES}

1. Stofkova A. Resistin and visfatin: regulators of insulin sensitivity, inflammation and immunity. Endocr Regul 2010;44:25-36.

2. Versini M, Jeandel PY, Rosenthal E, Shoenfeld Y. Obesity in autoimmune diseases: not a passive bystander. Autoimmun Rev 2014;13:981-1000.

3. Otero M, Lago R, Gomez R, Lago F, Dieguez C, Gómez-Reino JJ, et al. Changes in plasma levels of fat-derived hormones adiponectin, leptin, resistin and visfatin in patients with rheumatoid arthritis. Ann Rheum Dis 2006;65:1198-201.

4. Crowson CS, Matteson EL, Davis JM 3rd, Gabriel $\mathrm{SE}$. Contribution of obesity to the rise in incidence of rheumatoid arthritis. Arthritis Care Res (Hoboken) 2013;65:71-7.

5. Ajeganova S, Andersson ML, Hafström I; BARFOT Study Group. Association of obesity with worse disease severity in rheumatoid arthritis as well as with comorbidities: a long-term followup from disease onset. Arthritis Care Res (Hoboken) 2013;65:78-87.

6. Ljung L, Rantapää-Dahlqvist S. Abdominal obesity, gender and the risk of rheumatoid arthritis - a nested case-control study. Arthritis Res Ther 2016;18:277.

7. Gremese E, Carletto A, Padovan M, Atzeni F, Raffeiner B, Giardina AR, et al. Obesity and reduction of the response rate to anti-tumor necrosis factor $\alpha$ in rheumatoid arthritis: an approach to a personalized medicine. Arthritis Care Res (Hoboken) 2013;65:94-100.

8. Sandberg ME, Bengtsson C, Källberg $H$, Wesley A, Klareskog L, Alfredsson L, et al. Overweight decreases the chance of achieving good response and low disease activity in early rheumatoid arthritis. Ann Rheum Dis 2014;73:2029-33.

9. Heimans L, van den Broek M, le Cessie S, Siegerink B, Riyazi N, Han KH, et al. Association of high body mass index with decreased treatment response to combination therapy in recent-onset rheumatoid arthritis patients. Arthritis Care Res (Hoboken) 2013;65:1235-42.

10. Klaasen R, Wijbrandts CA, Gerlag DM, Tak PP. Body mass index and clinical response to infliximab in rheumatoid arthritis. Arthritis Rheum 2011;63:359-64.

11. Iannone F, Fanizzi R, Notarnicola A, Scioscia C, Anelli MG, Lapadula G. Obesity reduces the drug survival of second line biological drugs following a first TNF- $\alpha$ inhibitor in rheumatoid arthritis patients. Joint Bone Spine 2015;82:187-91. 
12. Okada Y, Terao C, Ikari K, Kochi Y, Ohmura K, Suzuki A, et al. Meta-analysis identifies nine new loci associated with rheumatoid arthritis in the Japanese population. Nat Genet 2012;44:511-6.

13. Sakai F, Noma S, Kurihara Y, Yamada H, Azuma A, Kudoh S, et al. Leflunomide-related lung injury in patients with rheumatoid arthritis: imaging features. Mod Rheumatol 2005;15:173-9.

14. WHO Expert Consultation. Appropriate body-mass index for Asian populations and its implications for policy and intervention strategies. Lancet 2004;363:157-63.

15. Aletaha D, Neogi T, Silman AJ, Funovits J, Felson DT, Bingham CO 3rd, et al. 2010 Rheumatoid arthritis classification criteria: an American College of Rheumatology/European League Against Rheumatism collaborative initiative. Arthritis Rheum 2010;62:2569-81.

16. Jih J, Mukherjea A, Vittinghoff E, Nguyen TT, Tsoh JY, Fukuoka Y, et al. Using appropriate body mass index cut points for overweight and obesity among Asian Americans. Prev Med 2014;65:1-6.

17. Sasazuki S, Inoue M, Tsuji I, Sugawara Y, Tamakoshi A, Matsuo K, et al. Body mass index and mortality from all causes and major causes in Japanese: results of a pooled analysis of 7 large-scale cohort studies. J Epidemiol 2011;21:417-30.

18. Steinbrocker O, Traeger $\mathrm{CH}$, Batterman $\mathrm{RC}$. Therapeutic criteria in rheumatoid arthritis. J Am Med Assoc 1949;140:659-62.

19. Felson DT, Smolen JS, Wells G, Zhang B, van Tuyl LH, Funovits J, et al. American College of Rheumatology/ European League Against Rheumatism provisional definition of remission in rheumatoid arthritis for clinical trials. Arthritis Rheum 2011;63:573-86.

20. Fransen J, van Riel PL. The Disease Activity Score and the EULAR response criteria. Clin Exp Rheumatol 2005;23:S93-9.

21. Kanda Y. Investigation of the freely available easy-touse software 'EZR' for medical statistics. Bone Marrow Transplant 2013;48:452-8.

22. Choe JY, Bae J, Lee H, Park SH, Kim SK. Lack association of body mass index with disease activity composites of rheumatoid arthritis in Korean population: cross-sectional observation. Clin Rheumatol 2014;33:485-92.

23. Hanley MJ, Abernethy DR, Greenblatt DJ. Effect of obesity on the pharmacokinetics of drugs in humans. Clin Pharmacokinet 2010;49:71-87.

24. Jhun JY, Yoon BY, Park MK, Oh HJ, Byun JK, Lee $\mathrm{SY}$, et al. Obesity aggravates the joint inflammation in a collagen-induced arthritis model through deviation to Th17 differentiation. Exp Mol Med 2012;44:424-31.

25. Alzabin S, Abraham SM, Taher TE, Palfreeman A, Hull $\mathrm{D}$, McNamee $\mathrm{K}$, et al. Incomplete response of inflammatory arthritis to TNF $\alpha$ blockade is associated with the Th17 pathway. Ann Rheum Dis 2012;71:1741-8.

26. Shan J, Zhang J. Impact of obesity on the efficacy of different biologic agents in inflammatory diseases: A systematic review and meta-analysis. Joint Bone Spine 2019;86:173-83.

27. Vidal C, Barnetche T, Morel J, Combe B, Daïen C. Association of Body Mass Index Categories with Disease Activity and Radiographic Joint Damage in Rheumatoid Arthritis: A Systematic Review and Metaanalysis. J Rheumatol 2015;42:2261-9.

28. Yamazaki K, Suzuki E, Yorifuji T, Tsuda T, Ohta T, Ishikawa-Takata $\mathrm{K}$, et al. Is there an obesity paradox in the Japanese elderly population? A community-based cohort study of 13280 men and women. Geriatr Gerontol Int 2017;17:1257-64. 